\title{
Three decades of wildlife radio telemetry in India: a review
}

\author{
Bilal Habib ${ }^{1 *}$, Shivam Shrotriya ${ }^{1}$, Kuppusamy Sivakumar ${ }^{1}$, Priya R Sinha ${ }^{2}$ and Vinod B Mathur ${ }^{1}$
}

\begin{abstract}
From 1983, there have been three decades of the application and development of radio telemetry for wildlife studies in India. In this article, we review 82 studies from India, covering 47 species from four taxonomic classes. We examine and discuss the trends in the selection of study species, habitats and objectives of radio-telemetry studies and the functional success of radio collars and tags. A strong bias for study species and study region is observed and researchers generally tend not to look beyond the traditional research questions. Habitats that are difficult to access, such as the Trans-Himalayas, the Himalayas and north-eastern India, are overlooked. Most of the studies aimed to infer primary information only, such as home range, migration and movement patterns and habitat preference $(53.7 \%, 47.6 \%$ and $28.1 \%$ studies, respectively). We expect these trends to change with time as the development of technology allows researchers to explore further. We investigated the tracking histories of 483 animals and the records of 496 radio collars or tags, but detailed information could be acquired for only 330 collars or tags. Of the collars, 49\% malfunctioned before the end of their anticipated life due to a variety of reasons, early battery drainage being the prevalent cause. The performance of different technologies and collar manufacturers was also analysed but the small sample size was an issue for most of the cases. Argos-based collars and tags generally failed to record most of the locations precisely and failed to transmit them successfully. Issues with permissions and capturing animals for tagging, particular to India, are also discussed. A uniform and centralized system for granting permissions and guidelines for capturing and handling animals would be beneficial to future telemetry studies.
\end{abstract}

Keywords: Battery drainage, Collar performance, India, Permission procedure, Radio collars, Research gap, Wildlife tracking

\section{Background}

Radio-telemetry technology and tracking methods for studying the behaviour and ecology of wild animals have advanced significantly since radio telemetry was first used in the 1960s [1]. Initially very high frequency (VHF) radio devices were used for wildlife tracking, which were limited to a range of only a few kilometres. Later, tagged individuals were tracked over continental distances using satellites. Though satellite telemetry was used as early as 1970, when an elk (Cervus canadensis) was collared and tracked in Wyoming [2], it became popular in wildlife research only after 1978 when the Argos satellite system became available for civilian use [3]. The reduction in the size and weight of satellite

\footnotetext{
*Correspondence: bh@wii.gov.in

'Wildlife Institute of India, Post Box No 18, Chandrabani, Dehradun 248001, Uttarakhand, India

Full list of author information is available at the end of the article
}

transmitter, that is platform terminal transmitters (PTTs) and the better quality of data transmission make satellite telemetry highly useful in studying even small migratory animals, such as birds, turtles and insects (for example, $[4,5])$. Previously, it had been limited to large animals due to the large attachment devices [6]. The weight of VHF telemeters has also reduced, and the smallest commercial VHF tag now available weighs only $0.19 \mathrm{~g}$, making it possible to tag even insects [7].

Satellite telemetry uses ultra-high frequency (UHF) radio signals, transmitted and tracked by polar-orbiting satellites run by the US National Oceanic and Atmospheric Administration. PTT locations are obtained with a quality index assigned to each location. The locations in classes 3 , 2, 1 and 0 have an estimated error of 150,350, 1,000 and $>1,000 \mathrm{~m}$ respectively, but no accuracy range is ascribed to locations in classes A, B and Z [8]. Global Positioning System (GPS) collars and tags were introduced 
to wildlife tracking in 1994 [9]. These tags have an inbuilt GPS receiver and use the Navstar GPS to locate an animal. GPS locations can be downloaded via VHF and UHF and recently via other satellite systems such as Argos, Immarsat, Iridium and Globalstar [3,10]. GPS-GSM (Global System for Mobile Communications) technology is a step further. It uses the GSM mobile phone network to facilitate communication between the collar and the receiver. GPS-GSM collars also provide control over the schedule of the fixes since commands can be sent and received via the Short Message Service [11]. Light-level geolocators or global location sensing (GLS) units are recent alternatives to GPS. Geolocators use the time of sunrise and sunset, which are unique to a particular location on earth, to estimate the geographic position of an animal [12].

In India, radio telemetry for wildlife was introduced much later. LD Mech, from the US Fish and Wildlife Service, brought the technology to India in 1976 for training and testing. Under the auspices of Project Tiger, two sambars (Rusa unicolor), three nilgai (Boselaphus tragocamelus), two chitals (Axis axis) and one wild boar (Sus scrofa) were collared and tracked from 1976 to 1980. Further in 1980, one Asiatic elephant (Elephas maximus), one tiger (Panthera tigris) and one Asiatic lion (Panthera leo persica) were also radio-collared and tracked. After the initial training, the telemetry equipment was left with Project Tiger personnel to track these animals and practise the technique. A Handbook of Animal Radio-Tracking was published based on these experiences, although results of these projects were not published [13]. The first full-fledged radio-telemetry study was carried out in 1983 by the Crocodile Research Centre of the Wildlife Institute of India at Hyderabad. This study successfully tagged and tracked 12 gharials (Gavialis gangeticus) in the Chambal River [14], which marks the beginning of such studies in India.

In this article, we present a review of the radiotelemetry studies conducted in India so far. Our aim in conducting this study was to collect the information on radio-telemetry projects in India at one place, which otherwise would be scattered and difficult to access. New projects do not benefit from the information generated in earlier projects because much of the data is still unpublished and research gaps are not well understood in the absence of such a compilation. We focussed on the trends in the selection of study species, habitats and objectives of radio-telemetry studies and assessed the functional success of devices, which could benefit future research. Issues with permissions and capturing animals for tagging, particular to India, were also considered in order to ignite discussions on how these could be better handled in future. A total of 82 studies, from 1983 to 2013, are reviewed here. Studies on different species from the same project are considered as separate. The tracking histories of 483 animals were investigated and information about 496 radio-tags is collected, analysed and presented in this article. Details of radio-collaring studies conducted or ongoing in India from 1983 to 2013 are provided in Additional file 1 and a summary is given in Table 1 .

\section{Review}

Information on radio-collars, radio-tags and transmitters was collected from published research papers, reports and dissertations and by contacting the investigators and researchers involved in radio-telemetry projects. Online surveys (powered by Survey Monkey [15]) were also conducted to collect information and the views of scientists and researchers on the permission process and capturing animals for tagging. Information was gathered for 496 collars and tags but the details were insufficient to evaluate the performance of all the collars. The transmitters were supplied by 13 manufacturers, Telonics $(n=179)$, Sirtrack $(n=75)$ and Advanced Telemetry Systems $(n=46)$ being the major providers; however, the manufacturer's information was not available for 63 transmitters (Table 2). We grouped the radio-collars and radio-tags used in India into four types: (1) conventional VHF, (2) Argos-only (PTT tags and collars), (3) GPS collars with an Argos uplink and (4) GPS collars with an Iridium uplink or ground download utility via VHF, UHF or GSM-network. Detailed information was available for 221 VHF collars, 82 Argos-only tags, 15 GPS-Argos collars, 4 GPS-Iridium collars, 8 GPS-ground download collars and 5 GPSGSM collars.

Uniformity in the format of details could not be maintained as the information originated from various sources. The collars and tags, therefore, were evaluated by a relative comparison of functional success. The functional success of the collars was calculated from the anticipated and functional lifespans. The expected lifespan of a collar is that given by the manufacturer and the anticipated lifespan was adjusted if the animal died, the collar was dropped or damaged or the project completed before the end of the collar's life. The functional life of a collar is the duration of deployment on an animal. The functional success of a collar is calculated as the functional life divided by the anticipated life. The functional life of a

Table 1 Summary of radio-telemetry studies conducted in India from 1983 to 2013

\begin{tabular}{lcccc}
\hline Animal class & Studies & Species & Animals tagged & Collars used \\
\hline Mammalia & 57 & 28 & 314 & 321 \\
Aves & 14 & 11 & 55 & 55 \\
Reptilia & 10 & 7 & 113 & 119 \\
Pisces & 1 & 1 & 1 & 1 \\
Total & 82 & 47 & 483 & 496 \\
\hline
\end{tabular}


Table 2 Number of collars used in India per manufacturer

\begin{tabular}{lc}
\hline Manufacturer & Number of collars \\
\hline Advanced Telemetry Systems & 46 \\
African Wildlife Tracking & 2 \\
AVM Instruments & 24 \\
Biotrack & 11 \\
HABIT & 18 \\
Holohil Ltd & 2 \\
Lotek & 3 \\
Nippon & 8 \\
Sirtrack & 75 \\
Telonics & 179 \\
Vectronics & 17 \\
Wildlife Computers & 1 \\
Wildlife Materials & 36 \\
Locally made & 11 \\
No information & 63 \\
Total & 496 \\
\hline
\end{tabular}

collar that was reused was calculated by totalling the duration of each use. Collars and tags still in use were not evaluated. The overall functional success of the collars from one manufacturing company was averaged for individual collars, using a maximum functional success of $100 \%$, so that if any collar performed beyond its expected life, it did not compensate for underperforming collars.

The performance of Argos-only tags was calculated as the ratio of the number of useful locations and the total number of locations obtained. We considered only the locations classed 3, 2, 1 and 0 as useful. Since the transmission windows for these tags were programmed for different situations, we did not use the standard 68-percentile method to determine collar performance $[16,17]$. Ratios for individual tags were averaged to give the ratio for a particular manufacturer. For the GPS-Argos collars and tags, the performance of only the Argos uplink could be assessed. The performance of the GPS receivers could not be assessed as most of the collars are either currently in use or could not be retrieved after the collars had stopped transmitting and the locations stored on board have been lost. The performance of the Argos uplink was calculated as the ratio of the number of locations obtained through the Argos system to the total number of locations expected to be recorded by the GPS receiver. The number of expected GPS locations was calculated as [3]:

(24 hours/GPS interval for obtaining a location) $\times$ Number of days the collar worked

The average Argos performance for each manufacturer is the mean of the performances of individual collars.
We recorded the reason for failure of each collar and tag in the field, if any. The reasons are grouped into three categories: (1) mechanical failure (if the collar was dropped or damaged), (2) technical failure (if there was a failure in transmission of the signal or the battery drained earlier than expected) and (3) unknown reasons, where the cause of the failure could not be ascertained.

\section{Results and discussion}

\section{Trends in the application of radio telemetry}

Since 1983, 82 studies have covered 47 species from four taxonomic classes (Table 1, Additional file 1). Charismatic and large species, in general, are a popular choice for telemetry studies in India. For instance, 57 out of the 82 studies were on mammals. Though 28 mammalian species (6.62\% of the total of 423 mammalian species found in India [18]) are covered in these studies, most are confined to a few well-known species. The tiger is the most studied species with nine studies collaring 40 individuals. The first radio-telemetry study on the tiger took place in 1990 in Nagarhole National Park (NP) [19]. In addition, five studies on the leopard (Panthera pardus; 18 individuals collared) and two studies on the Asiatic lion (13 individuals collared), compared to only seven studies on their major prey species, which are the wild pig, chital, sambar, nilgai and four-horned antelope (Tetracerus quadricornis) (altogether 19 individuals collared), clearly show that marginally less focus is given to small ungulates. Among large ungulates, the Asiatic elephant has had the most attention with eight studies collaring 36 individuals. The one-horned rhinoceros (Rhinoceros unicornis), gaur (Bos gaurus) and wild ass (Equus hemionus khur) remain on the margins with one study, two studies and one study, respectively. The use of advanced devices has also been largely limited to carnivores. GPS collars with a UHF ground download and Iridium satellite uplink were first used on the Asiatic lion from 2002 to 2009 (YV Jhala, unpublished data). GPS-GSM technology was introduced into India in 2007 to monitor a leopard rescued from a conflict [20]. Implanted radio-tags were used for the smooth-coated otter (Lutrogale perspicillata) from 1990 to 1992 [21]. Six Indian flying foxes (Pteropus giganteus) were tagged in 1985 but the results were not published; this is the only radio-telemetry study on Chiroptera (SP Goyal, unpublished data). Similarly, the Malabar spiny dormouse (Platacanthomys lasiurus) among rodents and the slender loris (Loris tardigradus) among primates are the only species covered to date [22,23].

Telemetry studies on birds were limited until the advent of satellite telemetry. Only 11 avian species (14 studies) out of the 1,375 species found in Indian subcontinent [24], that is less than $1 \%$, have been radiomonitored. In 1987, the white crested kalij (Lophura leucomelanos hamiltoni) became the first bird species to 
be monitored using VHF telemetry [25] followed by swamp francolin (Francolinus gularis) in 1988 [26]. Satellite tags were first used in 1993 and 1994 to track the Eurasian crane (Grus grus) from Keoladeo NP to their breeding grounds in Siberia [27]. Though the first wildlife radio-tracking study in India was on reptiles, on the gharial in 1985 [14], the next study on reptiles took place after a long gap when four olive ridley turtles (Lepidochelys olivacea) were tracked using satellite telemetry in 2001 [28]. So far only seven species of reptiles have been radio-tagged under ten different studies. A whale shark tagged in 2011 off the western coast of Gujarat is the only fish species (Wildlife Trust of India, unpublished data).

Not only species bias, but habitat bias is also prevalent. The Asiatic elephant was the first large animal collared in India (in 1985 in Mudumalai Wildlife Sanctuary) [29] and seven more studies followed using radio telemetry. However, these studies were restricted to only a few places (four studies in Rajaji NP and two in Buxa-Jaldapara Tiger Reserve), despite the wide distribution of elephants in India. The snow leopard (Uncia uncia), found in the Trans-Himalayan region, has never been tracked again after one unsuccessful attempt [30]. The habitats and regions with difficult terrain and approach, such as the Trans-Himalayas, the Himalayas and north-eastern India, have had fewer telemetry studies compared to the plains and approachable habitats (Table 3). A number of animal groups, let alone species, are yet to be studied in some habitats.

The species bias in telemetry studies can be attributed to certain factors. The first and foremost cause is that the cost of telemetry devices is quite high and funding is generally available for charismatic species only. Deployment was easier for large species as the early devices were not sophisticated and suitable enough for other species. With recent reductions in costs and advances in technology, this trend should change and conservation priority should be the major factor in deciding the study species. Many species with a high conservation value, such as the snow leopard, lion-tailed macaque (Macaca silenus), Indian wild buffalo (Bubalus arnee), red panda (Ailurus fulgens), dugong (Dugong dugon) and great Indian bustard (Ardeotis nigriceps), are yet to receive the care this technology offers. India has a great diversity of birds and there is still much to learn from using radio-tags. Studies of animal groups, such as chiropterans, primates, aquatic animals, herpetofauna, arthropods and other lower forms, are easier with the advances in radio devices. The Trans-Himalayas, Himalayas and northeastern India are repositories of a unique biodiversity, where exploration will benefit conservation.

Home range estimation, migration and movement patterns and habitat preference are the primary results of telemetry studies; however, these data can answer more specific and unique ecological questions, for example, disease transmission [31], predation and co-evolution [32], socio-ecology and breeding behaviour [33], sleep characteristics [34] and physiological studies [35]. In India, most of the studies have centred on the abovementioned primary questions $(53.7 \%, 47.6 \%$ and $28.1 \%$ of studies, respectively). Only a few recent studies have looked further at hibernation [36], den shifting [37], social organization [38] and monitoring translocated and rehabilitated individuals [39]; however, the number of such studies remains low (Table 4). A poorly planned study often brings to the unnecessary use of telemetry where obvious results are presented as a final outcome. If study questions are selected wisely and the study is planned well, single deployment of collars can provide a significant amount of information. Often the sample size appears to be overlooked, perhaps due to costs or administrative difficulties in obtaining permission to collar or tag animals. The number of animals tagged should be adequate for statistical tests since the true sample size is the number of animals and not the number of locations. A recommended sample size to make inference on comparison of two populations is 20 animals. Similarly resource selection, survival with known fate and realistically complex population studies require a sample size of 30, 50 to 100 and $>75$ animals, respectively. These recommendations still do not address the representativeness of a sample based on actual population size (in [40]) [41-43].

\section{Collar performance}

The performance of collars and tags is affected by a number of factors such as animal behaviour, environmental factors, habitat type, material used for the collar, configuration and type of battery used, variation in the position of the collar or tag and the location of the antenna on the animal's body. Because of the unavailability of the precise details of the use of collars and tags and the low sample size in many cases, we were unable to consider many such aspects.

\section{Performance of VHF collars}

The success rate of VHF collars was quite high, as only a simple transmitter is involved. The average functional success per manufacturer is presented in Table 5. Manufacturers where less than five collars were used are not listed. Equipment from Advanced Telemetry Systems, Wildlife Materials and Telonics were comparatively reliable, with success rates of $100 \%, 96 \%$ and $86 \%$, respectively. Locally made VHF collars (assembled by the researchers) were successfully used to study five grey francolins (Francolinus pondicerianus) and six black 
Table 3 Number of studies in different habitat types

\begin{tabular}{|c|c|c|c|c|c|c|c|c|c|}
\hline Habitat & Carnivores & Herbivores & Chiroptera & Rodents & Primates & Birds & Reptiles & Fish & Total \\
\hline Trans-Himalayas & 1 & 1 & - & - & - & - & - & - & 2 \\
\hline Himalayas & 2 & - & - & - & - & 4 & - & - & 6 \\
\hline Gangetic Plain & - & 4 & 1 & - & - & 5 & - & - & 10 \\
\hline Arid and semi-arid regions & 11 & 5 & - & - & - & 4 & - & - & 20 \\
\hline North-east & 2 & 4 & - & - & - & - & - & - & 6 \\
\hline Mangroves, coastal and riverine regions & 2 & - & - & - & - & - & 6 & 1 & 9 \\
\hline Western ghats & 3 & 1 & - & 1 & 1 & 1 & 3 & - & 10 \\
\hline Deccan Plateau & 12 & 6 & - & - & - & - & - & - & 18 \\
\hline Islands & - & - & - & - & - & - & 1 & - & 1 \\
\hline
\end{tabular}

francolins (Francolinus francolinus) and these worked for five to seven months [44].

\section{Performance of Argos-only tags}

Most of the data in this review came from the study on olive ridley turtles in the Bay of Bengal and along the Sri Lankan coast [5]. We compared the performance of Argos-only collars and tags using ratio as index (Table 6). The functional success of Telonics devices was the highest (100\%), but the sample size was small. The performance of the Argos system is highly variable across places and success is dependent on the location of the antenna and the availability of over-passes of the satellites [45,46]. Argos satellites pass over India about 25 times a day and each pass lasts for about 10 to 15 minutes [8]. However, the performance of the Argos satellite system in India and elsewhere is questionable as it does not perform uniformly in all parts of its coverage and the problems have not been resolved [3,47-49]. PTTs perform better at higher elevations and altitudes [16], therefore, these are more useful for studying migratory birds.

\section{Performance of GPS-Argos collars}

The dataset for the GPS-Argos collars was too small to draw any inferences (Table 7). Argos uplink failure was the major problem with GPS-Argos collars. Most of the collars failed to transmit even half of the GPS locations to Argos. In particular, this drawback forces researchers to retrieve collars after the battery is exhausted and download the remaining data. However, most of the reports, generally, did not describe the use of drop-off devices. A GPS-Argos collar deployed on a tiger in Panna Tiger Reserve uplinked only 26 locations, but 264 locations were recovered on board after the collar had

Table 4 Ecological questions asked in various radio-telemetry studies in India

\begin{tabular}{|c|c|c|c|}
\hline Ecological question & Description of question & $\begin{array}{l}\text { Study animals } \\
\text { (number of studies) }\end{array}$ & $\begin{array}{l}\text { Percentage } \\
\text { of studies }\end{array}$ \\
\hline Demography & Population dynamics and survival rate estimation & Carnivores (2) & 2.4 \\
\hline Dispersal and spatial distribution & $\begin{array}{l}\text { Movement of sub-adults to new areas; pattern of } \\
\text { dispersion of the species }\end{array}$ & Carnivores (4) & 4.9 \\
\hline Social organization & Interrelationships of the group members & Carnivores (3) & 3.7 \\
\hline Competition & Spatial separation of sympatric carnivores & Carnivores (1) & 1.2 \\
\hline Habitat preference & Temporal and spatial use of habitat resources & $\begin{array}{l}\text { Carnivores (7), other mammals (11), } \\
\text { birds (5) }\end{array}$ & 28.1 \\
\hline Home range & $\begin{array}{l}\text { Estimation of area required for general activities } \\
\text { by individual or group }\end{array}$ & $\begin{array}{l}\text { Carnivores (23), other mammals (15), } \\
\text { birds (3), reptiles ( } 3 \text { ) }\end{array}$ & 53.7 \\
\hline Migration and movement patterns & $\begin{array}{l}\text { Monitoring seasonal movement over long distances; } \\
\text { spatio-temporal movement within home range }\end{array}$ & $\begin{array}{l}\text { Carnivores (14), other mammals (8), } \\
\text { birds (9), reptiles ( } 7) \text {, fish (1) }\end{array}$ & 47.6 \\
\hline Activity patterns & Time spent per activity or activity budget & Carnivores (7) & 8.5 \\
\hline Nesting and breeding behaviour & Behavioural observation on various aspects of breeding & Carnivore (1), birds (2), reptiles (1) & 4.9 \\
\hline Food habits & $\begin{array}{l}\text { Direct observation with additional information from } \\
\text { kill records and scat }\end{array}$ & $\begin{array}{l}\text { Carnivores (12), other mammals (1), } \\
\text { reptiles (3) }\end{array}$ & 19.5 \\
\hline Human-wildlife conflict & Monitoring movement of conflict animals & Carnivores (2), other mammals (1) & 3.7 \\
\hline Translocation and rehabilitation & $\begin{array}{l}\text { Monitoring the condition of translocated and } \\
\text { rehabilitated individuals }\end{array}$ & $\begin{array}{l}\text { Carnivores (4), other mammals (3), } \\
\text { reptiles (2) }\end{array}$ & 11.0 \\
\hline
\end{tabular}


Table 5 Functional success of VHF collars from various manufacturers

\begin{tabular}{llc}
\hline Manufacturer & Habitat and region & Percentage functional success (number of collars) \\
\hline Advanced Telemetry Systems & Riverine, Deccan Plateau & $100(43)$ \\
AVM instruments & Western ghats & $58(24)$ \\
HABIT & Arid & $39(06)$ \\
Telonics & Gangetic Plain, arid, Himalayas, Deccan Plateau, & $86(94)$ \\
Wildlife Materials & western ghats, north-east, riverine & $96(30)$
\end{tabular}

$\mathrm{VHF}$, very high frequency.

dropped off (K Ramesh, personal communication). Another collar on an Asiatic black bear in Dachigam NP sent only 12 locations via satellite, whereas 57 more locations were recovered after the collar had dropped off (S Sathyakumar, personal communication).

\section{Performance of other GPS collars}

GPS-Iridium collars from Vectronics were used to study tigers in Sunderban Tiger Reserve and Asiatic lions in Gir NP (YV Jhala, unpublished data). None of the four collars achieved the expected lifespan, 24 months in this case, due to early battery drainage and animal death. There were no major issues noted with the location uplink (YV Jhala, personal communication). Collars with a GPS ground download via VHF $(n=3)$ and UHF $(n=3)$ from HABIT and Vectronics, respectively, were used on Asiatic lions (YV Jhala, unpublished data) and tigers (K Sankar, unpublished data). Location data were obtained from these collars with complete success, but these collars also stopped before the expected lifespan. The Vectronics GPS ground download via UHF device $(n=3)$ used to study leopards in Dachigam NP performed well (B Habib, unpublished data). GPS-GSM collars $(n=5)$ from Vectronics were used to study leopards in Nasik by Athreya et al. [19]. All the locations obtained by GPS in these collars were sent over the GSM network successfully and numbered over 8,900. In general, these collars performed well in transmitting the data but failed due to early battery drainage.

\section{Causes of failure}

Out of 330 collars, for which information on causes of failure during use was available, $49 \%(n=162)$ encountered problems (Table 8$)$. Of the collars, $21 \%(n=69)$ suffered technical problems (signal stopped or battery drained), and 6.4\% $(n=21)$ suffered mechanical problems (collar or tag dropped, antenna or collar damaged). There were unknown reasons for failure for $21.8 \%$ of the collars $(n=72)$. For the PTTs deployed on the olive ridley and green turtles, there are various possible reasons for failure. Tagged turtles may become entangled in fishing nets, the collar may detach from the carapace and fall into the sea, the battery may drain or there could be technical problems with the transmitters. Apparently the major reason for collar failure in most of the studies was battery drainage before the expected end of life. Weather conditions can affect battery life, especially the high temperatures in arid, semi-arid and Deccan Plateau regions where most of the collars were used. We could not ascertain the effect of habitat type on the performance of the technology in India due to insufficient data.

Experimental tests of collar performance in the field are required to improve the technology. Manufacturers should look for a solution for the early battery drainage, specifically for tropical conditions. VHF devices are the best for large animals with confined home ranges. Lightweight VHF transmitters can be successfully used for ground-dwelling birds. The performance of Argos-based systems remains in question and researchers should use other devices if possible. If affordable, GPS-based devices with either other satellite systems or a ground download facility via VHF, UHF or a GSM network are recommended.

\section{Permission and animal capture issues in India}

Despite the invaluable help offered by radio telemetry in animal conservation, government agencies still hesitate

Table 6 Performance of Argos-only tags and collars

\begin{tabular}{llc}
\hline Manufacturer & Species & $\begin{array}{c}\text { Ratio of useful locations to locations } \\
\text { obtained (number of studies) }\end{array}$ \\
\hline Nippon & Bar-headed goose & $\begin{array}{c}\text { Percentage functional } \\
\text { success (number of studies) }\end{array}$ \\
Sirtrack & Olive ridley turtle and green turtle & $0.14(2)$ \\
Telonics & Bar-headed goose & $0.28(67)$ \\
& Asiatic elephant & $0.53(4)$ \\
\hline
\end{tabular}

${ }^{a}$ Collars that detached or failed for unknown reasons are included. 
Table 7 Performance of Argos in GPS-Argos uplink collars and their functional success

\begin{tabular}{lccccc}
\hline Manufacturer & $\begin{array}{c}\text { Expected number } \\
\text { of GPS locations }\end{array}$ & $\begin{array}{c}\text { Number of locations } \\
\text { received by Argos }\end{array}$ & $\begin{array}{c}\text { Percentage performance for } \\
\text { Argos (number of collars) }\end{array}$ & $\begin{array}{c}\text { Percentage functional success } \\
\text { (number of collars) }\end{array}$ \\
\hline Telonics & 812 & 582 & $46(4)$ & GPS-Argos & VHF beacon \\
Lotek & 199 & 67 & $34(2)$ & $800(4)$ & $100(4)$ \\
Vectronics & 720 & 650 & $90(1)$ & $4(1)$ & $32(2)$ \\
\hline
\end{tabular}

GPS, global positioning system.

to grant permission for such studies since the technology is invasive, involving capturing and handling the target species, whose population in the wild may be small. We asked researchers to rank the permission process in India as easy, difficult or very difficult. Of the respondents, $60 \%$ ranked the process as difficult and very difficult. The issues regarding permissions for scientific research in India were discussed in detail by Madhusudan et al. [50]. Government policies have improved since then, yet the issues have not been resolved satisfactorily. We believe that new guidelines issued by the Ministry of Environment and Forests, Government of India, for scientific studies in protected areas [51] offer some relief to researchers. However, permission for radio-collaring has to go through various agencies at state and national levels and state governments have yet to comply with the new guidelines. There is a necessity for a centralized and uniform system to grant permissions and for guidelines for capturing and handling wild animals. Centralizing the permission system would give an element of predictability to the outcome of proposals put forward by researchers. The guidelines should consider the conservation status of the species and the criticality of the information proposed to be collected.

Animals may experience negative effects due to collaring [52-54], though this issue is debatable [55,56]. So far mortality during immobilization and radio-collaring has been remarkably low in India. In some unfortunate cases of mortality occurring during radio-collaring, the press and media in India generated an acrimonious debate over the use of radio-telemetry as a tool. In the first such incident, five tigers died after two months of a collaring exercise in Nagarhole NP. However, investigations revealed no relation between the radio-collaring and mortality. One tiger died due to pulmonary disease, one was old and three others died in territorial fights on different occasions. Only one of these tigers was collared, and three of the four collared tigers were alive during this incident $[57,58]$. Criticism of radio-collaring is misplaced considering the success during tranquilization and collaring in the majority of the studies. It is also relevant to mention that the assessment of the health and metabolic activity of an animal to be restrained is based on an ocular estimation and the probability of rare accidents cannot be reduced to zero. The World Health Organisation has reported that medical errors are one of the top causes of mortality in hospitals [59], but this does not cause us to stop medical interventions. The key is to weigh the benefits of telemetry studies to the overall population and for conservation rather than consider individual animal-specific issues.

\section{Conclusions}

The fundamental issue in any invasive research is the criticality of the information proposed to be collected and its relevance to the overall conservation of the species. Therefore the data generated should be of good quality and easily accessible to all concerned. We believe that researchers also need to be aware of the entire gamut of issues relating to radio telemetry. Our experience during this review is that details of study methodology and the specification of equipment are not readily available. It was also observed that a large amount of data is either missing or there is a reservation among the researchers to share the data. In view of the rapid development of radio-telemetry tools, managers and researchers should have easy access to the performance parameters of the new tools to enable them to choose appropriate devices for their study. Often low funding for conservation projects and problems with the permission process for such studies do not allow researchers to access new technology. The prejudged efficacy of such technology in Indian conditions, on the basis of the experience of other researchers, will obviate the uncertainties involved in using a particular device. Keeping proper records of collaring and tagging and sharing data amongst researchers would also help future studies. These will give clear and useful feedback to the manufacturers as well, so that they can improve the quality and performance parameters of their products. Information on the failure of collars should be discussed freely and should not be interpreted as a failure of the research projects. Discussion of positive and negative experiences would help to refine the technology and improve its efficiency. Coordination amongst the institutions in India and individual researchers working in wildlife research and information technology holds promise that this technology can be adapted for India with enhanced efficiency and reduced costs and it will be less invasive in use. 
Table 8 Reasons for failure of collars and tags

\begin{tabular}{|c|c|c|c|c|c|c|c|}
\hline Manufacturers and technology & $\begin{array}{l}\text { Number } \\
\text { of collars }\end{array}$ & $\begin{array}{l}\text { Collars failed } \\
\text { during use (\%) }\end{array}$ & $\begin{array}{l}\text { Collars } \\
\text { dropped }\end{array}$ & $\begin{array}{l}\text { Antenna broken } \\
\text { or collar damaged }\end{array}$ & $\begin{array}{c}\text { Signal } \\
\text { stopped }\end{array}$ & $\begin{array}{l}\text { Battery } \\
\text { drained }\end{array}$ & $\begin{array}{l}\text { Contact lost } \\
\text { or unknown }\end{array}$ \\
\hline
\end{tabular}

Advanced Telemetry Systems

AHF

VHF beacon

$46 \quad 6.5$

6.52

GPS-UHF

AVM Instruments

VHF

VHF backpack

\section{Biotrack}

VHF

\section{HABIT}

VHF

GPS-VHF

GPS-UHF

Holohil Ltd

VHF implant

\section{Lotek}

$\mathrm{VHF}$ beacon

GPS-Argos

Nippon

PTT backpack

Sirtrack

PTT backpack

Telonics

VHF

VHF implant

PTT backpack

VHF beacon

Argos-only

GPS-Argos

$\begin{array}{cc}96 & 27 \\ 4 & 100 \\ 4 & 0 \\ 5 & 0 \\ 1 & 100 \\ 9 & 11\end{array}$

Vectronics

VHF beacon

GPS-Argos

GPS-Iridium

GPS-UHF

GPS-GSM

\section{Wildlife Computers}

PTT backpack

Wildlife Materials

VHF

$\begin{array}{cc}30 & 26.7 \\ \mathbf{3 3 0} & \mathbf{4 9 . 1}\end{array}$

100

100

75

100

80

5

Total

330
100

26.72

8
-
-
-
1
1

17

4

19

50 


\section{Additional file}

\section{Additional file 1: Details of radio-collaring studies conducted or} ongoing in India from 1983 to 2013.

\section{Abbreviations}

GLS: Global location sensing; GPS: Global positioning system; GSM: Global system for mobile communications; NP: National park; PTT: Platform terminal transmitter; UHF: Ultra-high frequency; VHF: Very high frequency.

\section{Competing interests}

The authors declare that they have no competing interests.

\section{Authors' contributions}

$\mathrm{BH}$ conceived this review of Indian telemetry studies. $\mathrm{BH}$ formulated and structured the article. SS collected the information and literature and wrote the article. KS, PRS and VBM provided critical input at the conceptualisation and final stages. All authors participated in collection of the information and were involved in subsequent revisions of the manuscript. All authors read and approved the final manuscript.

\section{Acknowledgements}

We thank all the scientists and researchers who shared their data used in this review. Special thanks are due to the Wildlife Institute of India, with particular mention of Dr SP Goyal, for help with the literature search and access to the data. We are thankful to Dr LD Mech for his comments on initial draft of the article. We thank the reviewers for their comments for improving the manuscript.

\section{Author details}

${ }^{1}$ Wildlife Institute of India, Post Box No 18, Chandrabani, Dehradun 248001, Uttarakhand, India. ${ }^{2}$ Country representative, IUCN-India country office, B-88, Neeti Bagh, New Delhi 110049, India.

Received: 30 August 2013 Accepted: 20 February 2014

Published: 28 February 2014

\section{References}

1. Cochran $\mathrm{WW}$, Lord RD Jr: A radio tracking system for wild animals. J Wildl Manage 1963, 27:9-24.

2. Craighead FC Jr, Craighead JJ, Cote CE, Buechner HK: Satellite and ground radio tracking of Elk. In Animal Orientation and Navigation. NASA SP-262. Edited by Galler SR. Washington DC: NASA; 1972:99-111.

3. Kaczensky $P$, Ito TY, Walzer C: Satellite telemetry of large mammals in Mongolia: what expectations should we have for collar function? Wildl Biol Pract 2010, 6:108-126.

4. Fuller M, Seegar WS, Howey PW: The use of satellite systems for the study of bird migration. Isr J Zool 1995, 41:243-252

5. Sivakumar K, Choudhury BC, Kumar RS, Behera SK, Behera S, John S, Ola VP: Application of satellite telemetry techniques in sea turtle research in India. In Telemetry in Wildlife Science. Edited by Sivakumar K, Habib B. Dehradun, India: Wildlife Institute of India; 2010:140-145 [ENVIS Bulletin: Wildlife and Protected Areas, vol 13, no 1.].

6. Fancy SG, Pank LF, Douglas DC, Curby CH, Garner GW, Amstrup SC, Regelin WL: Satellite Telemetry: A New Tool for Wildlife Research and Management, Resource Publication No 172. Washington, DC: US Fish and Wildlife Service; 1988.

7. Wall S: The development and advantages of coded telemetry. In Telemetry in Wildlife Science. Edited by Sivakumar K, Habib B. Dehradun, India: Wildlife Institute of India; 2010:31-34 [ENVIS Bulletin: Wildlife and Protected Areas, vol 13, no 1.].

8. Argos: User's Manual. Toulouse, France: CLS/Service, Argos; 1996

9. Rodgers AR: Tracking animals with GPS: the first 10 years. In Tracking Animals with GPS. Proceedings of an International Conference Held at the Macaulay Land Use Research Institute, 12-13 March 2001; Aberdeen, SD, USA 2001:1-10.

10. Brugnoli A, Alberti M, Rocca M: Linx individual B132 from north-eastern Switzerland sighted in Trentino (northern Italy). Forest@ 2008, 5:172-269.

11. Sundell J, Kojola I, Hanski I: A New GPS-GSM-based method to study behavior of brown bears. Wildlife Soc B 2006, 34:446-450.
12. Burger $A E$, Shaffer $S A$ : Application of tracking and data-logging technology in research and conservation of seabirds. Auk 2008, 125:253-264.

13. Mech LD: Handbook of Animal Radio-Tracking. MN: University of Minnesota Press; 1983.

14. Singh LAK: Ghariyal Population Trend in National Chambal Sanctuary With Notes on Radio-Tracking. Report. Hyderabad, India: Crocodile Research Centre of Wildlife Institute of India; 1985.

15. SurveyMonkey. [http://www.surveymonkey.com]

16. Keating AK, Brewster WG, Key $\mathrm{CH}$ : Satellite telemetry: performance of animal-tracking systems. J Wildl Manage 1991, 55:160-171.

17. Hays GC, Akesson S, Godley BJ, Luschi P, Santidrian P: The implication of location accuracy for the interpretation of satellite-tracking data. Anim Behav 2001, 61:1035-1040.

18. Sharma G, Kamalakannan M, Venkataraman K: A Checklist of Mammals of India with their Distribution and Conservation Status. ZSI e-publication. Kolkata, India: Zoological Society of India; 2013

19. Karanth KU, Sunquist ME: Behavioural correlates of predation by tiger (Panthera tigris), leopard (Panthera pardus) and dhole (Cuon alpinus) in Nagarahole, India. J Zool Lond 2000, 250:255-265.

20. Athreya $V$, Odden M, Linnell J: Using GPS-GSM collars to understand leopard movements in a human-dominated landscape in Amhednagar district, Western Maharashtra. In Telemetry in Wildlife Science. Edited by Sivakumar K, Habib B. Dehradun, India: Wildlife Institute of India; 2010:52-55 [ENVIS Bulletin: Wildlife and Protected Areas, vol 13, no 1.].

21. Hussain SA: Aspects of the Ecology of Smooth Coated Otter Lutra perspicillata in National Chambal Sanctuary, PhD thesis. Aligarh Muslim University; 1993.

22. Jayson EA: Status, Distribution, Food and Feeding of Malabar Spiny Dormouse (Platacanthomys lasiurus Blyth) in the Western Ghats of Kerala, KFRI Research Report No. 293. Thrissur, India: Kerala Forest Research Institute; 2006.

23. Kar Gupta K: Social-Ecology and Conservation of Slender Loris (Loris tardigradus) in Southern India, PhD thesis. Arizona State University; 2007.

24. Grimmett R, Inskipp C, Inskipp T, Allen R: Birds of Indian Subcontinent Christopher Helm; 2011.

25. Sharma V: Ecology and Conservation of Pheasants in Shimla Hills, Himachal Pradesh, PhD thesis. Panjab University; 1990.

26. Iqubal P, McGowan PJK, Rahmani AR: Home range size, habitat use and nesting success of swamp francolin Fracolinus gularis on agricultural land in northern India. Bird Conserv Int 2003, 13:127-138.

27. Higuchi $H$, Nagendran M, Sorokin AG, Ueta M: Satellite tracking of common cranes Grus grus migrating north from Keoladeo National Park, India. In Proceedings of the International Symposium on the Future of Cranes and Wetlands; Tokyo, Japan. Edited by Higuchi H, Minton J. 1994:26-31.

28. Shanker K, Choudhury BC, Pandav B, Tripathi B, Kar CS, Kar SK, Gupta NK, Frazia JG: Tracking olive-ridley turtle from Orissa. In Proceedings of the 22nd Annual Symposium on Sea Turtle Biology and Conservation, NOAA Technical Memorandum NMFS-SEFSC - 503. Edited by Seminoff JA. 2003:50-51.

29. Desai AA: The home range of elephants and its implications for management of the Mudumalai Wildlife Sanctuary, Tamil Nadu. J Bombay Nat Hist Soc 1991, 88:145-156.

30. Chundawat RS: Ecological Studies of Snow Leopard and its Associated Prey Species in High Altitude National Park (J \& K), PhD thesis. University of Rajasthan; 1992.

31. Cheeseman $\mathrm{CL}$, Mallinson PJ: Radio tracking in the study of bovine tuberculosis in badgers. In A Handbook on Biotelemetry and Radio-Tracking. Edited by Amlaner J Jr, MacDonald DW. Oxford: Pergamon Press; 1980:649-656.

32. Mech LD: Telemetry as a technique in the study of predation. J Wildl Manage 1967, 31:492-496.

33. Mech LD: Making the most of radiotracking. In A Handbook on Biotelemetry and Radio-Tracking. Edited by Amlaner J Jr, MacDonald DW. Oxford: Pergamon Press; 1980:85-95.

34. Schmidt DF, Shaffery JP, Ball NJ, Lonennke D, Amlaner CJ Jr: Electrophysiological sleep characteristics in bobwhite quail. In Proceedings of the Tenth International Symposium on Biotelemetry, Volume X Edited by Amlaner CJ Jr. Fayetville: University of Arkansas Press; 1989:339-344

35. Kreeger TJ, Kuechlem VB, Mech LD, Tester JR, Seal US: Physiological monitoring of grey wolves (Canis lupus) by radio telemetry. J Mammal 1990, 71:259-261.

36. Charoo SA, Sharma LK, Sathyakumar S: Investigations on the Ecology of the Asiatic Black Bear (Ursus thibetanus) in Dachigam National Park, 
Kashmir, India: an overview. In International Conference on Wildlife and Biodiversity Conservation vis-à-vis Climate Change. Srinagar, Jammu and Kashmir, India. ; 2010.

37. Habib B, Kumar S: Den shifting by wolves in semi-wild landscapes in the Deccan Plateau, Maharashtra, India. J Zool 2007, 272:259-265.

38. Meena $\mathrm{V}$, Jhala $\mathrm{Y}$ : Radio-telemetry studies on lions in India. In Telemetry in Wildlife Science, Volume 13, no. 1. Edited by Sivakumar K, Habib B. Dehradun, India: Wildlife Institute of India; 2010:48-51.

39. Kumar U: Ecological Aspects of Re-Introduced Great Indian One-Horned Rhinoceros Rhinoceros unicornis in Manas National Park, Assam, MSc thesis. Aligarh Muslim University; 2009.

40. Hebblewhite M, Haydon DT: Distinguishing technology from biology: a critical review of the use of GPS telemetry data in ecology. Phil Trans $R$ Soc B 2010, 365:2303-2312.

41. Lindberg MS, Walker J: Satellite telemetry in avian research and management: sample size consideration. J Wild Manage 2007, 71:1002-1009.

42. Leban FA, Wisdom MJ, Garton EO, Johnson BK, Kie JG: Effect of sample size on the performance of resource selection analyses. In Radio Tracking and Wildlife Populations. Edited by Millspaugh JJ, Marzluff JM. New York: Academic; 2001:291-307.

43. Murray DL: On improving telemetry-based survival estimation. J Wildl Manage 2006, 70:1530-1543.

44. Kalsi RS: The successful use of radio-transmitters made in India. In Third International Galliformes Symposium - 2004, 5-10 April, 2004; India. Dehra Dun and Corbett National Park, Uttaranchal: Wildlife Institute of India; 2004.

45. Britten MW, Kennedy PL, Ambrose S: Performance and accuracy evaluation of small satellite transmitters. J Wildl Manage 1999, 63:1349-1358.

46. Dubinin M, Lushchekina A, Raeloff VC: Performance and accuracy of Argos transmitters for wildlife monitoring in southern Russia. Eur J Wildlife Res 2010, 56:459-463.

47. Gros P, Malarde JP, Woodward B: Argos Performance in Europe part II, Tracker News. Microwave Telemetry Inc; Spring 2006. http://www. microwavetelemetry.com/uploads/newsletters/spring_06page8.pdf.

48. McCarthy T: Snow Leopard Update from Dr. Tom McCarthy: Radio Noise Hampers Satellite-Based Study of Snow Leopards in Asia. Asia-Pacific Regional Space Agency Forum (APRSAF); 2006 [http://www.aprsaf.org/interviews_features/ features_2007/feature_19.php]

49. Anon: Updates, Tracker News. Microwave Telemetry Inc; Winter 2007. http:// www.microwavetelemetry.com/uploads/newsletters/winter07page6.pdf.

50. Madhusudan MD, Shanker K, Kumar A, Mishra C, Sinha A, Arthur R, Datta A, Rangarajan M, Chellam R, Shahabuddin G, Sankaran R, Singh M,

Ramakrishnan U, Rajan PD: Science in the wilderness: the predicament of scientific research in India's wildlife reserves. Curr Sci 2006, 91:1015-1019.

51. Guidelines for scientific research in the wildlife protected areas. [http://moef.nic.in/sites/default/files/guidelines_scientific.pdf]

52. Aldridge HDJN, Brigham RM: Load carrying and manoeuvrability in an insectivorous bat: a test of the $5 \%$ 'rule' of radio-telemetry. J Mammal 1988, 69:379-382.

53. Massey BW, Keane K, Bordman C: Adverse effects of radio transmitters on the behavior of nesting least terns. Condor 1988, 90:945-947.

54. Guthery FS, Lusk JJ: Radio-telemetry studies: are we radio-handicapping northern bobwhites? Wildlife Soc B 2004, 32:194-201.

55. Gorman ML, Mills MGL, French J: Satellite tracking of the African wild dog Lycaon pictus. In Wildlife Telemetry Remote Monitoring and Tracking of Animals. Edited by Priede IG, Swift SM. New York: Ellis Horwood; 1992:218-228.

56. Folk TH, Grand JB, Palmer WE, Carroll JP, Sisson DC, Terhune TM, Wellendorf SD, Stribling HL: Estimates of survival from radio telemetry: a response to guthery and lusk. J Wild Manage 2007, 71:1027-1033.

57. Panwar HS, Cheeran JV, Gopal T: Report of Expert Committee Appointed by Government of Karnataka to Review the Research Project 'Ecology and Management of Larger Carnivores' in Nagarhole National Park. Bangalore, India: Government of Karnataka; 1991

58. Sukumar R: The Nagarhole tiger controversy. Curr Sci 1991, 59:1213-1216.

59. World Health Organization: World Alliance for Patient Safety: Forward Programme 2005. Switzerland; 2005.

\section{Submit your next manuscript to BioMed Central and take full advantage of:}

- Convenient online submission

- Thorough peer review

- No space constraints or color figure charges

- Immediate publication on acceptance

- Inclusion in PubMed, CAS, Scopus and Google Scholar

- Research which is freely available for redistribution 